\title{
Progress in elucidating the pathophysiological basis of nonrapid eye movement parasomnias: not yet informing therapeutic strategies
}

This article was published in the following Dove Press journal:

Nature and Science of Sleep

8 March 2016

Number of times this article has been viewed

\section{András Horváth ${ }^{1,2}$ \\ Anikó Papp' \\ Anna Szűcs'}

'Department of Neurology, National Institute of Clinical Neurosciences, 2János Szentágothai Doctoral School of Neurosciences, Semmelweis University School of PhD Studies, Budapest, Hungary
Correspondence: Anna Szücs Department of Neurology, National Institute of Clinical Neurosciences, I I 44 Budapest, Amerikai út 57, Hungary Tel +36 30684262

Email szucsan@gmail.com

\begin{abstract}
Nonrapid eye movement (NREM) or arousal parasomnias are prevalent conditions in children and young adults, apparently provoked by any medical, physical, mental, or pharmacologic/toxic agent disturbing normal biorhythm and causing sleep fragmentation or abundant amount of slow wave sleep. The nadir and the ascending slope of the first sleep cycle of night sleep are the typical periods when NREM parasomnias, especially sleepwalking may occur on sleep-microstructural level; microarousals are the typical moments allowing NREM parasomnias. While sleep-disturbing factors have a clear precipitating effect, a genetic predisposition appears necessary in most cases. A candidate gene for sleepwalking has been identified on chromosome 20q12-q13.12 in one sleepwalking family. NREM parasomnias have a genetic and clinical link with nocturnal-frontal lobe epilepsies; possibly through an abnormality of the acetylcholine-related sleep-control system. The association of NREM parasomnias with the human leukocyte antigen system might be the sign of an autoimmune background to be further clarified. In the treatment of arousal parasomnias, the main tools are adequate sleep hygiene and the management of underlying conditions. Their pharmacotherapy has remained unresolved; the best options are clonazepam and some of the antidepressants, while a psychotherapy approach is also justified.
\end{abstract}

Keywords: sleep disorders, arousal disorders, NREM parasomnia, sleepwalking, sleep terror

\section{Introduction}

Parasomnias are undesirable physical or behavioral events within, and in the transitions to and from sleep. Classically, they are grouped into nonrapid eye movement (NREM) sleep or arousal parasomnias (APs); those related to rapid eye movement sleep (REM); and parasomnias having no sleep state preference.

$\mathrm{APs}^{1}$ represent dissociated states between NREM sleep and waking. Examples include confusional arousals, sleepwalking, and sleep terrors ${ }^{2}$ with significant overlap. An occurrence in the first third of the night, total or partial amnesia to the events, and the lack of dreaming are classically considered diagnostic, however, the lack of dreaming has been challenged recently. ${ }^{3-6}$

APs typically manifest during childhood affecting more than $13 \%$ of children; the prevalence in young adults is $1 \%-4 \%$. The lifetime prevalence of sleepwalking may be as high as $30 \%{ }^{7}$ Based on a Norwegian population study, the lifetime prevalence of the different APs varied from 4\% to 67\%; for sleepwalking, lifetime prevalence was $22.4 \%$ and the current prevalence was $1.7 \%$. For other parasomnias, lifetime and current prevalences were as follows: sleep talking $66.8 \%$ and $17.7 \%$, confusional arousal $18.5 \%$ and $6.9 \%$, sleep terror $10.4 \%$ and $2.7 \%$, injured during sleep $4.3 \%$ and 
$0.9 \%$, injured somebody else during sleep $3.8 \%$ and $0.4 \%$, sexual acts during sleep $7.1 \%$ and $2.7 \%$, and sleep-related eating $4.5 \%$ and $2.2 \%{ }^{8}$

Sleepwalking patients typically walk quietly around the flat, then clean, pack, undress, and dress; may eat, ${ }^{9}$ drink, or have sex. ${ }^{10}$ The events last some minutes to half an hour. Many patients, mainly children, just walk from one bed to another during sleep; some adults may do long drives. It is the leading cause of sleep-related violence and self-harm. ${ }^{11-13}$

Patients with sleep terror start suddenly from sleep with a scream; face and body expressing intense fear with autonomic signs like tachycardia and sweating; then they go back quietly to sleep without remembering the event later.

The aim of this review was to summarize the current conception of the background of NREM parasomnias and their treatment options based on new scientific findings.

Because APs have several common features with nocturnal-frontal lobe epilepsies (NFLEs), we compared and discussed the two groups of conditions sometimes together in this work.

\section{Sleep-structure and the control of sleep}

The "structure" of a night's sleep may be characterized on different levels. The concept of sleep macrostructure is based on Rechtschaffen's and Kales' sleep phases and is represented by the hypnogram, a cyclic pattern showing the sequence of sleep phases. ${ }^{14,15}$ The "microstructural" level underlying sleep macrocycles is made up of electroencephalogram (EEG) graphoelements like slow waves, $\mathrm{K}$ complexes, and sleep spindles; the building stones of more complex patterns as microarousals during NREM sleep ${ }^{16,17}$ and the cyclic alternating pattern (CAP) ${ }^{18} \mathrm{CAP}$ is considered the EEG-representation of a homeostatic control system of NREM sleep. ${ }^{19}$ The cellular level of sleep-oscillations has recently been studied. ${ }^{20}$

The sleep cycles are controlled by two reciprocal antagonistic systems: the wake-promoting ascending reticular system of the brainstem and the posterior hypothalamus on one hand, and the anterior hypothalamic sleep promoting system on the other. ${ }^{21}$ Sleep-wake control is realized by cholinergic, monoaminergic, and orexinergic projections originating from special nuclei of the brainstem/hypothalamus and reaching wide areas of the cortex via thalamocortical loops. ${ }^{22-25}$

\section{Genetic factors in APs}

APs are more frequent in the deep sleepers' families ${ }^{26}$ and long sleeping has a predisposition to parasomnias. ${ }^{27}$
Based on the recognition of the strong family-accumulation of sleepwalking, supported by population ${ }^{28-30}$ and twin studies, ${ }^{31,32}$ its genetic background has been intensively searched for.

Human leukocyte antigen DQ beta (HLA DQB) is associated with REM sleep behavior disorder (RBD) and especially with narcolepsy. ${ }^{33}$ Narcolepsy patients frequently have APs. ${ }^{34-37}$ In 2003, the first genetic susceptibility factor, the DQB1*0501 HLA gene was identified for sleepwalking. ${ }^{38}$ Thus, APs, RBD, and narcolepsy share the feature of HLA-association, possibly reflecting an abnormal sleep-related movement-control in general. These conditions also have some overlapping symptomatology $\mathrm{y}^{39,40}$ and pathomechanism; including the possibility of an autoimmune background. ${ }^{41-43}$

Based on the study of a four-generation family by genomewide multipoint parametric linkage analysis, a genetic locus for sleepwalking has been identified at chromosome 20q12q13.12; the phenotype was found to be transmitted as an autosomal dominant trait with reduced penetrance. ${ }^{44}$

In summary, progress has been made in attempting to identify the genetic basis of NREM parasomnias, however, further large-scale studies are necessary to definitely elucidate it.

\section{Links of APs and NFLEs}

A genetic overlap with NFLEs and APs has been proposed. In a study on 100 NFLEs cases, it was shown that 39 of them had a family history and 34 had a personal history for parasomnias. ${ }^{45}$ In another study on NFLEs patients/their families versus controls/their families, the lifetime prevalence of sleepwalking was significantly more frequent among NFLEs patients/their families compared with controls/their families. ${ }^{46}$ Childhood parasomnias turned to NFLEs later in life in many subjects. ${ }^{47}$

Both NFLEs and APs occur during NREM sleep, especially in deep slow wave sleep or Phase II; and are associated with CAP A. Both conditions may also present in sleep stage 1, during entry into sleep, or during partial arousals. ${ }^{48,49}$ The typical occurrence of sleepwalking is the turning point of deep NREM sleep, at the nadir of the first sleep cycle, preceded by delta hypersynchrony. ${ }^{50}$ (This timing is diagnostic in differentiating sleepwalking from REM parasomnias: somnambulism occurs about 1.5 hours after sleep onset, while REM parasomnias appear in the second half of the night during the predominance of REM sleep). A curious EEG pattern - anterior delta and posterior alpha activity - has been observed during APs. ${ }^{51}$ 


\section{Symptoms, overlap, and confusion of APs with NFLEs}

Besides the genetic link and shared sleep features, some diagnostic confusion about NFLEs and APs has taken place. Frontal lobe seizures are easily misdiagnosed for night terror or nightmares, and the poorly characterized outdated condition "nocturnal paroxysmal dystonia" or "fearful awakening" was identified as NFLEs later. ${ }^{52}$

One of the most straightforward ways for discriminating AP- and NFLE-related movements during sleep is the high frequency - up to 20-30 - of NFLEs events in a night versus the rare, maximum one/night AP event. ${ }^{53}$

Investigating the semiology of APs during video-EEG monitoring, 57 APs were detected and compared with 63 NFLE seizures. ${ }^{54}$

Three main types of APs were identified; most containing a combination of more than one pattern: 1) arousal behavior (4/5 of the events), eg, eye opening, head elevation, staring and face rubbing, yawning, stretching, moaning, and mumbling; 2) nonagitated motor behavior (3/4 of events) like sitting up, manipulating, and orienting with passive or perplexed face; occasional coherent speech; 3) distressed emotional behavior (half of the events): fear and anxiety expressed by facial expression and vocalization/speech; standing, screaming, and frantic/violent behavior. Attempts to restrict the sleepwalking persons frequently led to an aggressive response.

In contrast to sleepwalking that started with arousal-like phenomena in $80 \%$, half of NFLE seizures started abruptly from sleep. The movements seen in the two groups were similar and nondiagnostic. Tachycardia was typical in both groups (Table 1). ${ }^{55}$

A recently described curious clinical feature of sleepwalking is daytime sleepiness; not explained otherwise. ${ }^{56}$

\section{The pathophysiology of APs The serotonergic hypothesis}

Pathological imbalance of neurotransmitters involved in sleep regulation may lead to sleep dissociation, eg, RBD is suggested to precede and associate with parkinsonian conditions, especially Parkinson's disease featured by impaired dopamine routes. ${ }^{57,58}$

The involvement of the serotonergic system in sleepwalking has been hypothesized in the early 80 s by Barabas et al, ${ }^{59}$ supported later by the recognition of an altered serotonergic system in migraine. They noticed a surprisingly high prevalence of somnambulism in children suffering from migraine,
Table I APs and NFLEs: shared and discriminating features ${ }^{53,54}$

\begin{tabular}{|c|c|c|}
\hline & Arousal parasomnias & $\begin{array}{l}\text { Nocturnal frontal } \\
\text { lobe seizures }\end{array}$ \\
\hline $\begin{array}{l}\text { Typical sleep } \\
\text { phase, CAP }\end{array}$ & $\begin{array}{l}\text { NREM sleep phases, entry } \\
\text { into sleep, arousals; CAP A }\end{array}$ & $\begin{array}{l}\text { NREM sleep phases, } \\
\text { entry into sleep, } \\
\text { arousals; CAP A }\end{array}$ \\
\hline $\begin{array}{l}\text { Distribution during } \\
\text { night sleep }\end{array}$ & $\begin{array}{l}\text { Within } 2 \text { hours after sleep } \\
\text { onset }\end{array}$ & Anytime \\
\hline Frequency & I/night & I-30 per/night \\
\hline Onset & $\begin{array}{l}\text { After arousal-like } \\
\text { phenomena }\end{array}$ & Abruptly from sleep \\
\hline Triggering stimulus & $\ln 50 \%$ & $\ln 8 \%$ \\
\hline $\begin{array}{l}\text { Comprehensible } \\
\text { speech }\end{array}$ & Frequent & None \\
\hline Offset & $\begin{array}{l}\text { Followed by NREM sleep } \\
\text { in } 75 \%\end{array}$ & $\begin{array}{l}\text { Seizures woke the } \\
\text { patients }\end{array}$ \\
\hline Tachycardia & Yes & Yes \\
\hline Movement type & Nondiscriminating & Nondiscriminating \\
\hline
\end{tabular}

Abbreviations: APs, arousal parasomnias; CAP, cyclic alternating pattern; NFLEs, nocturnal-frontal lobe epilepsies; NREM, nonrapid eye movement.

a condition characterized by a tenfold presence of sleep disorders including sleep-breathing disorders, ${ }^{60}$ nightmares,${ }^{61}$ sleep talking, ${ }^{62}$ bruxism, ${ }^{63}$ and sleepwalking. ${ }^{64}$ There is growing evidence on chronic serotonin depletion in migraine, and a sudden, significant serotonin increase during migraine attacks. ${ }^{65}$ Microinjections of serotonin into the cholinergic basal neurons of rats induced an increase in the EEG delta activity and a sleepwalking-like behavior. ${ }^{66}$

Additional studies have supported the role of a serotonergic mechanism ${ }^{67}$ in sleepwalking, showing the provoking effect of febrile states, ${ }^{68}$ selective serotonin reuptake inhibitor drugs ${ }^{69}$ and lithium ${ }^{70}$ via the elevation of serotonin ratio. $^{71}$

\section{The cholinergic hypothesis, connecting APs with NFLEs}

Acetylcholine is the main neurotransmitter of cortical activation during arousal, including arousals in sleep. ${ }^{72-74}$ The thalamus and cortex are rich in cholinergic fibers, partially originating in the basal nucleus providing a strong cholinergic input. ${ }^{66}$

Some of the autosomal dominant NFLEs have been found to be caused by mutations of genes encoding the neuronal nicotinic acetylcholine receptor (AChR) subunits, resulting in increased AChR sensitivity. ${ }^{75,76}$ Changes in prefrontal $\gamma$-aminobutyric acid release and other than AChR genes have recently been described. ${ }^{77}$

The increased AChR sensitivity caused by the mutation moves the sleep-wake balance in the thalamocortical circuit towards cortical activation, resulting in the occurrence of 
CAP A and microarousals during NREM sleep, favoring both AP and frontal lobe seizures. ${ }^{78}$

Because autosomal dominant nocturnal frontal lobe epilepsy is a prototype of NFLEs, one may assume the contributory role of the cholinergic arousal system also in NFLEs in general. ${ }^{79,80}$ The clinical similarities of NFLEs and arousal parasomnias, their shared relationship with the sleep process and the genetic link, suggest a shared cholinergic mechanism. ${ }^{80}$

\section{The hypothetic mechanism of APs}

- The disinhibition of the basal ganglia due to the inactivation of the inhibitory frontal lobe during NREM sleep might result in the activation of central motor pattern generators, ${ }^{81}$ presenting their fixed movement patterns in "inappropriate" moments (eg, in sleep). ${ }^{16,79-81}$

- Sleep dissociation: it may affect a pattern or the "localization" of sleep.

Pattern dissociation is generally abnormal. ${ }^{82}$ It means the state-independent, inappropriate occurrence or lack of an element of a certain state pattern, for example, in RBD, REM sleep occurs without atonia allowing the sleeper to act out his/her dreams; in sleep paralysis, the REM sleep-related atonia is transitorily maintained after awakening, resulting in frightening lameness. ${ }^{16}$ Cataplexy is similar, but atonia may appear abruptly in a fully alert state, easily resulting in falls. ${ }^{83,84}$ During pattern dissociation of APs, the body is "awake" and the "mind" continues sleeping.

"Local" sleep dissociations, eg, coexistence of unequally deep sleeping/waking brain regions are normal responses to selective overuse, or may represent an adaptation to special circumstances. Local sleeps of different cortical columns ${ }^{85}$ may develop after specific activity of localized brain regions prior to sleep, resulting in a reactive increase of the delta sleep in those overactive regions. ${ }^{86}$ The alternating hemispheric sleep in dolphins and cetaceans ${ }^{87}$ represents the adaptation of the mammalian to life in water. The coexistence of sleeping and waking brain regions in APs has been demonstrated by a single-photon emission computed tomography study showing selective activation of the thalamocingulate pathways and simultaneous deactivation of other thalamocortical systems during a sleepwalking episode. ${ }^{88}$ Stereo EEG testing could also demonstrate local sleeps in parasomnias. ${ }^{89}$

- The pathological arousals with confusion and autonomic signs seen in APs might be consistent with emergency behaviors generated by an abnormal frontal cholinergic arousal system. ${ }^{79,90}$

\section{Medical conditions and environmental factors}

APs are provoked by sleep deprivation, sleep fragmentation, or disturbed sleep in the genetically predisposed person. ${ }^{11,12}$ Provoking factors include conditions and substances that fragment sleep or disturb regular biorhythm, for example, sleep-disturbing noises; alcohol; most illicit drugs; stress and fever; shift work or irregular lifestyle; anxiety, depressed mood, obsessive-compulsive or phobic traits; conditions causing sleep fragmentation, for example, sleep apnea and restless legs syndrome.91,92 "De novo" sleepwalking episodes have been described in hyperthyreosis, especially in acute thyrotoxicosis, ${ }^{93}$ vascular lesions of the brainstem, and the right thalamus. ${ }^{94}$

Different drugs may cause sleepwalking episodes: Z-drugs (zopiclone and zolpidem), serotonin-norepinephrine reuptake inhibitors, selective serotonin reuptake inhibitors, certain antiepileptic drugs (valproic acid and topiramate), tricyclic antidepressants, benzodiazepines, some antipsychotic drugs, lithium, sodium oxybate, beta-blockers, antihistamines, and even some antibiotics (ciprofloxacin). ${ }^{95}$

\section{Treatment Nonpharmacological treatment}

During clinical management of APs, the assessment of the condition's severity and a multidisciplinary approach is needed. The first step in the clinical evaluation is the mapping of possible comorbidities and underlying conditions. Elimination of precipitating factors is the main line of treatment; sleep apnea syndrome is a typical example. ${ }^{96}$ The reduction of upper airway resistance surprisingly diminishes the number of APs even without a full obstructive sleep apnea syndrome. ${ }^{97}$

Because sleep activity might be dangerous, the safe sleep environment including bedroom and windows is important. Alarmed bedroom doors and windows serve injury protection.

Childhood parasomnias generally resolve with no treatment in the adolescent period; an underlying sleep apnea syndrome is to be searched for and treated if present. ${ }^{98}$

The clinician has multidisciplinary tasks when managing APs; like education of regular life style, and tasks of specialist in addictology, general medicine and sleep-expert. The most important nonpharmacologic way of managing APs is reaching adequate sleep hygiene, avoiding sleep deprivation, and providing quiet sleeping conditions. Encourage the patients to create their own personalized sleep ritual 
and sleep-waking rhythm with a ready bedtime even on the weekends. ${ }^{99}$

Although the diagnosis of APs is generally easy and straightforward, it may sometimes be confusing, and a misdiagnosis for epilepsy or psychogenic spells may occur. In unclear cases, a thorough consideration, evaluation, and sleep tests may be necessary to find the diagnosis and have the best possible treatment. ${ }^{100}$ Psychotherapies-hypnosis, cognitive behavioral therapy, or relaxation or self-hypnosis may occasionally be helpful. ${ }^{101,102}$ Anticipatory awakening before the usual onset of sleepwalking events has proven to be effective in children. ${ }^{103}$

\section{Pharmacological therapy not yet informing therapeutic strategies}

There are just a few studies on clinical trials of the pharmacologic treatment of parasomnias, and their results are contradicting. ${ }^{104}$ The first-line drugs are sedato-hypnotics and antidepressants, drugs which could also provoke amnestic nocturnal behaviors. ${ }^{95} \mathrm{~A}$ trial with diazepam has shown an improvement in the self-reported frequency of nocturnal episodes, but there was no significant difference between the results of placebo and the diazepam-treated group. ${ }^{104}$ Most studies with clonazepam showed a significant decrease in the number of episodes; $\sim 80 \%$ of the affected patients reported nearly complete control. ${ }^{105}$

Numerous studies linked the use of antidepressants to the development of APs pointing out the provocative effect of paroxetine, mirtazapine, and bupropion. ${ }^{106} \mathrm{On}$ the other hand, an early study demonstrated the usefulness of imipramine in the control of somnambulism and night terror, ${ }^{107}$ and paroxetine was found to be effective in somnambulism. ${ }^{108}$ Another study did not demonstrate significant positive effect of sedative antidepressants in somnambulism. ${ }^{109}$

\section{Disclosure}

The authors report no conflicts of interest in this work.

\section{References}

1. Broughton RJ. Sleep disorders: disorders of arousal? Enuresis, somnambulism, and nightmares occur in confusional states of arousal, not in "dreaming sleep". Science. 1968;159(3819):1070-1078.

2. Medicine AAoS. Diagnostic and Coding Manual. Westchester, IL: American Academy of Sleep Medicine. International Classification of Sleep Disorders; 2005.

3. Uguccioni G, Golmard JL, de Fontréaux AN, Leu-Semenescu S, Brion A, Arnulf I. Fight or flight? Dream content during sleepwalking/sleep terrors vs rapid eye movement sleep behavior disorder. Sleep Med. 2013;14(5):391-398.
4. Dumitrascu O, Schenck CH, Applebee G, Attarian H. Parasomnia overlap disorder: a distinct pathophysiologic entity or a variant of rapid eye movement sleep behavior disorder? A case series. Sleep Med. 2013; 14(11):1217-1220.

5. Manni R, Terzaghi M. Dreaming and enacting dreams in nonrapid eye movement and rapid eye movement parasomnia: a step toward a unifying view within distinct patterns? Sleep Med. 2013;14(5):387-388.

6. Bhat S, Chokroverty S, Kabak B, Yang QR, Rosen D. Dream-enacting behavior in non-rapid eye movement sleep. Sleep Med. 2012;13(4): 445-446.

7. Ohayon MM, Mahowald MW, Dauvilliers Y, Krystal AD, Léger D. Prevalence and comorbidity of nocturnal wandering in the US adult general population. Neurology. 2012;78(20):1583-1589.

8. Bjorvatn B, Grønli J, Pallesen S. Prevalence of different parasomnias in the general population. Sleep Med. 2010;11(10):1031-1034.

9. Brion A, Flamand M, Oudiette D, Voillery D, Golmard J-L, Arnulf I. Sleep-related eating disorder versus sleepwalking: a controlled study. Sleep Med. 2012;13(8):1094-1101.

10. Organ A, Fedoroff JP. Sexsomnia: sleep sex research and its legal implications. Curr Psychiatry Rep. 2015;17(5):1-8.

11. Zadra A, Pilon M, Montplaisir J. Polysomnographic diagnosis of sleepwalking: effects of sleep deprivation. Ann Neurol. 2008;63(4): 513-519.

12. Pressman MR. Factors that predispose, prime and precipitate NREM parasomnias in adults: clinical and forensic implications. Sleep Med Rev. 2007;11(1):5-30.

13. Siclari F, Khatami R, Urbaniok F, et al. Violence in sleep. Brain. 2010; 133(12):3494-3509.

14. Rechtschaffen A, Kales A. A Manual of Standardized Terminology, Techniques and Scoring System of Sleep Stages in Human Subjects. Los Angeles: Brain Information Service/Brain Research Institute, University of California; 1968.

15. Carskadon MA, Rechtschaffen A. Monitoring and staging human sleep. In: Kryger M, Roth T, Dement WC, editors. Principles and Practice of Sleep Medicine. 3rd ed. Philadelphia: WB Saunders; 2000:1203-1206.

16. Parrino L, Halasz P, Tassinari CA, Terzano MG. CAP, epilepsy and motor events during sleep: the unifying role of arousal. Sleep Med Rev. 2006;10(4):267-285.

17. Terzano M, Mancia D, Salati M, Costani G, Decembrino A, Parrino L. The cyclic alternating pattern as a physiologic component of normal NREM sleep. Sleep. 1985;8:137-145.

18. Halasz P, Bodizs R. Dynamic Structure of NREM Sleep. London: Springer Science and Business Media; 2012.

19. Terzano MG, Parrino L, Sherieri A, et al. Atlas, rules, and recording techniques for the scoring of cyclic alternating pattern (CAP) in human sleep. Sleep Med. 2001;2(6):537-553.

20. Bordas C, Kovacs A, Pal B. The M-current contributes to high threshold membrane potential oscillations in a cell type-specific way in the pedunculopontine nucleus of mice. Front Cell Neurosci. 2015;9:121.

21. Saper CB, Chou TC, Scammell TE. The sleep switch: hypothalamic control of sleep and wakefulness. Trends Neurosci. 2001;24(12): 726-731.

22. Kohlmeier KA, Tyler CJ, Kalogiannis M, et al. Differential actions of orexin receptors in brainstem cholinergic and monoaminergic neurons revealed by receptor knockouts: implications for orexinergic signaling in arousal and narcolepsy. Front Neurosci. 2013;7:246.

23. Ishibashi M, Gumenchuk I, Kang B, et al. Orexin receptor activation generates gamma band input to cholinergic and serotonergic arousal system neurons and drives an intrinsic $\mathrm{Ca} 2+-$ dependent resonance in LDT and PPT cholinergic neurons. Front Neurol. 2015;6:120.

24. Sakurai T, Amemiya A, Ishii M, et al. Orexins and orexin receptors: a family of hypothalamic neuropeptides and $\mathrm{G}$ protein-coupled receptors that regulate feeding behavior. Cell. 1998;92(4):573-585.

25. Yamanaka A, Beuckmann CT, Willie JT, et al. Hypothalamic orexin neurons regulate arousal according to energy balance in mice. Neuron. 2003;38(5):701-713. 
26. American Academy of Sleep Medicine. International Classification of Sleep Disorders - third edition (ICSD-3). AASM Resource Library; 2014.

27. Oluwole O. Lifetime prevalence and incidence of parasomnias in a population of young adult Nigerians. J Neurol. 2010;257(7):1141-1147.

28. Abe K, Shimakawa M. Predisposition to sleep-walking. Psychiatr Neurol (Basel). 1966;152(5):306-312.

29. Abe K, Amatomi M, Oda N. Sleepwalking and recurrent sleeptalking in children of childhood sleepwalkers. Am J Psychiatry. 1984;141:800-801.

30. Kales A, Soldatos CR, Bixler E, et al. Hereditary factors in sleepwalking and night terrors. Br J Psychiatry. 1980;137(2):111-118.

31. Bakwin H. Sleep-walking in twins. Lancet. 1970;296(7670): 446-447.

32. Hublin C, Kaprio J. Genetic aspects and genetic epidemiology of parasomnias. Sleep Med Rev. 2003;7(5):413-421.

33. Dauvilliers Y, Maret S, Tafti M. Genetics of normal and pathological sleep in humans. Sleep Med Rev. 2005;9(2):91-100.

34. Dauvilliers Y, Billiard M, Montplaisir J. Clinical aspects and pathophysiology of narcolepsy. Clin Neurophysiol. 2003;114:2000-2017.

35. Ferri R, Miano S, Bruni O, et al. NREM sleep alterations in narcolepsy/ cataplexy. Clin Neurophysiol. 2005;116:2675-2684.

36. Plazzi G, Serra L, Ferri R. Nocturnal aspects of narcolepsy with cataplexy. Sleep Med Rev. 2008;12:109-128.

37. Mayer G, Meier-Ewert K. Motor dyscontrol in sleep of narcoleptic patients (a lifelong development?). J Sleep Res. 1993;2:143-148.

38. Lecendreux M, Bassetti C, Dauvilliers Y, Mayer G, Neidhart E, Tafti M. HLA and genetic susceptibility to sleepwalking. Mol Psychiatry. 2003;8(1):114-117.

39. Popat S, Winslade W. While you were sleepwalking: science and neurobiology sleep disorders and the enigma of legal responsibility of violence during parasomnia. Neuroethics. 2015;8(2):203-214.

40. Szücs A, Kamondi A, Zoller R, Barcs G, Szabó P, Purebl G. Violent somnambulism: a parasomnia of young men with stereotyped dreamlike experiences. Med Hypotheses. 2014;83(1):47-52.

41. De la Herrán-Arita AK, Kornum BR, Mahlios J, et al. CD4+T cell autoimmunity to hypocretin/orexin and cross-reactivity to a 2009 H1N1 Influenza A epitope in narcolepsy. Sci Transl Med. 2013;5(216):216ra176.

42. Gough S, Simmonds MJ. The HLA region and autoimmune disease: associations and mechanisms of action. Curr Genomics. 2007;8(7): 453-465.

43. Hosomichi K, Shiina T, Tajima A, Inoue I. The impact of nextgeneration sequencing technologies on HLA research. J Hum Genet. 2015:665-673.

44. Licis A, Desruisseau D, Yamada K, Duntley S, Gurnett C. Novel genetic findings in an extended family pedigree with sleepwalking. Neurology. 2011;76(1):49-52.

45. Provini F, Plazzi G, Tinuper P, Vandi S, Lugaresi E, Montagna P. Nocturnal frontal lobe epilepsy. A clinical and polygraphic overview of 100 consecutive cases. Brain. 1999;122(6):1017-1031.

46. Bisulli F, Vignatelli L, Naldi I, et al. Increased frequency of arousal parasomnias in families with nocturnal frontal lobe epilepsy: a common mechanism? Epilepsia. 2010;51(9):1852-1860.

47. Tinuper P, Provini F, Bisulli F, Lugaresi E. Hyperkinetic manifestations in nocturnal frontal lobe epilepsy. Semeiological features and physiopathological hypothesis. Neurol Sci. 2005;26(3):s210-s214.

48. Tassinari CA, Gardella E, Cantalupo G, Rubboli G. Relationship of central pattern generators with parasomnias and sleep-related epileptic seizures. Sleep Med Clin. 2012;7(1):125-134.

49. Oldani A, Zucconi M, Asselta R, et al. Autosomal dominant nocturnal frontal lobe epilepsy. Brain. 1998;121:205-223.

50. Montagna P, Provini F, Bisulli F, Tinuper P. Nocturnal epileptic seizures versus the arousal parasomnias. Somnologie (Berl). 2008;12(1):25-37.

51. Jaar O, Pilon M, Carrier J, Montplaisir J, Zadra A. Analysis of slowwave activity and slow-wave oscillations prior to somnambulism. Sleep. 2010;33(11):1511-1516.
52. Derry CP, Harvey AS, Walker MC, Duncan JS, Berkovic SF. NREM arousal parasomnias and their distinction from nocturnal frontal lobe epilepsy: a video EEG analysis. Sleep. 2009;32(12):1637-1644.

53. Zucconi M, Ferini-Strambi L. NREM parasomnias: arousal disorders and differentiation from nocturnal frontal lobe epilepsy. Clin Neurophysiol. 2000;111:S129-S135.

54. Zucconi M, Oldani A, Ferini-Strambi L, Bizzozero D, Smirne S. Nocturnal paroxysmal arousals with motor behaviors during sleep: frontal lobe epilepsy or parasomnia? J Clin Neurophysiol. 1997;14(6): 513-522.

55. Halász P, Kelemen A, Szűcs A. Physiopathogenetic interrelationship between nocturnal frontal lobe epilepsy and NREM arousal parasomnias. Epilepsy Res Treat. 2012; 2012:312693.

56. Desautels A, Zadra A, Labelle M-A, Dauvilliers Y, Petit D, Montplaisir J. Daytime somnolence in adult sleepwalkers. Sleep Med. 2013;14(11): 1187-1191.

57. Olson EJ, Boeve BF, Silber MH. Rapid eye movement sleep behaviour disorder: demographic, clinical and laboratory findings in 93 cases. Brain. 2000;123(2):331-339.

58. Ylikoski A, Martikainen K, Partinen M. Parasomnias and isolated sleep symptoms in Parkinson's disease: a questionnaire study on 661 patients. J Neurol Sci. 2014;346(1):204-208.

59. Barabas G, Ferrari M, Matthews WS. Childhood migraine and somnambulism. Neurology. 1983;33:948-949.

60. Kelman L, Rains JC. Headache and sleep: examination of sleep patterns and complaints in a large clinical sample of migraineurs. Headache. 2005;45(7):904-910.

61. Lippman CW. Recurrent dreams in migraine: an aid to diagnosis. J Nerv Ment Dis. 1954;120(3-4):273-276.

62. Cevoli S, Giannini G, Favoni V, Pierangeli G, Cortelli P. Migraine and sleep disorders. Neurol Sci. 2012;33(1):43-46.

63. Fernandes G, Franco AL, Gonçalves DA, Speciali JG, Bigal ME, Camparis CM. Temporomandibular disorders, sleep bruxism, and primary headaches are mutually associated. J Orofac Pain. 2013;27(1): 14-20.

64. Miller V, Palermo T, Powers S, Scher M, Hershey A. Migraine headaches and sleep disturbances in children. Headache. 2003;43(4):362-368.

65. Terron JA. Is the 5-HT7 receptor involved in the pathogenesis and prophylactic treatment of migraine? Eur J Pharmacol. 2002;439:1-11.

66. Cape EG, Jones BE. Differential modulation of high-frequency $\gamma$-electroencephalogram activity and sleep-wake state by noradrenaline and serotonin microinjections into the region of cholinergic basalis neurons. J Neurosci. 1998;18(7):2653-2666.

67. Kales JD, Kales A, Soldatos CR, Chamberlin K, Martin ED. Sleepwalking and night terrors related to febrile illness. Am J Psychiatry. 1979;136(9):1214-1215.

68. Kawashima T, Yamada S. Paroxetine-induced somnambulism. J Clin Psychiatry. 2003;64(4):483.

69. Landry P, Warnes H, Nielsen T, Montplaisir J. Somnambulisticlike behaviour in patients attending a lithium clinic. Int Clin Psychopharmacol. 1999;14(3):173-176.

70. Price LH, Charney DS, Delgado PL, Heninger GR. Lithium and serotonin function: implications for the serotonin hypothesis of depression. Psychopharmacology. 1990;100(1):3-12.

71. Juszczak GR, Swiergiel AH. Serotonergic hypothesis of sleepwalking. Med. Hypotheses. 2005;64(1):28-32.

72. Celesia GG, Jasper HH. Acetylcholine released from cerebral cortex in relation to state of activation. Neurology. 1966;16(11):1053-1053.

73. Muzur A, Pace-Schott EF, Hobson JA. The prefrontal cortex in sleep. Trends Cogn Sci. 2002;6(11):475-481.

74. Montplaisir JY. Cholinergic mechanisms involved in cortical activation during arousal. Electroenceph Clin Neurophysiol. 1975;38(3): 263-272.

75. Shiba Y, Mori F, Yamada J, et al. Spontaneous epileptic seizures in transgenic rats harboring a human ADNFLE missense mutation in the $\beta 2$-subunit of the nicotinic acetylcholine receptor. Neurosci Res. 2015;100:46-54. 
76. Itier V, Bertrand D. Mutations of the neuronal nicotinic acetylcholine receptors and their association with ADNFLE. Neurophysiol Clin. 2002;32(2):99-107.

77. Aridon P, Marini C, Di Resta C, et al. Increased sensitivity of the neuronal nicotinic receptor $\alpha 2$ subunit causes familial epilepsy with nocturnal wandering and ictal fear. Am J Hum Genet. 2006;79(2):342-350.

78. Becchetti A, Aracri P, Meneghini S, Brusco S, Amadeo A. The role of nicotinic acetylcholine receptors in autosomal dominant nocturnal frontal lobe epilepsy. Front Physiol. 2015;6:22.

79. Halász P, Kelemen A, Szücs A. The role of NREM sleep micro-arousals in absence epilepsy and in nocturnal frontal lobe epilepsy. Epilepsy Res. 2013;107(1):9-19.

80. Hogan RE, Kaiboriboon K. The "dreamy state": John HughlingsJackson's ideas of epilepsy and consciousness. Am J Psychiatry. 2003; 160(10):1740-1747.

81. Tassinari CA, Rubboli G, Gardella E, et al. Central pattern generators for a common semiology in fronto-limbic seizures and in parasomnias. A neuroethologic approach. Neurol Sci. 2005;26(3):225-232.

82. Petrovic J, Lazic K, Ciric J, Kalauzi A, Saponjic J. Topography of the sleep/wake states related EEG microstructure and transitions structure differentiates the functionally distinct cholinergic innervation disorders in rat. Behav Brain Res. 2013;256:108-118.

83. Mahowald MW, Schenck CH. Status dissociatus: a perspective on states of being. Sleep. 1991;14(1):69-79.

84. Meletti S, Vaudano AE, Pizza F, et al. The brain correlates of laugh and cataplexy in childhood narcolepsy. J Neurosci. 2015;35(33): 11583-11594.

85. Krueger JM, Obál F, Kapás L, Fang J. Brain organization and sleep function. Behav Brain Res. 1995;69(1):177-185.

86. Kattler H, Dijk DJ, Borbely AA. Effect of unilateral somatosensory stimulation prior to sleep on the sleep EEG in humans. J Sleep Res. 1994;3(3):159-164.

87. Mukhametov L, Supin AY, Polyakova I. Interhemispheric asymmetry of the electroencephalographic sleep patterns in dolphins. Brain Res. 1977;134(3):581-584.

88. Bassetti C, Vella S, Donati F, Wielepp P, Weder B. SPECT during sleepwalking. Lancet. 2000;356(9228):484-485.

89. Gibbs SA, Proserpio P, Terzaghi M, et al. Sleep-related epileptic behaviors and non-REM-related parasomnias: insights from stereo-EEG. Sleep Med Rev. Epub 2015 May 19.

90. Borbély AA, Achermann P. Sleep homeostasis and models of sleep regulation. J Biol Rhythms. 1999;14(6):559-570.

91. Guilleminault C, Palombini L, Pelayo R, Chervin RD. Sleepwalking and sleep terrors in prepubertal children: what triggers them? Pediatrics. 2003;111(1):e17-e25.

92. Ohayon MM, Guilleminault C, Priest RG. Night terrors, sleepwalking, and confusional arousals in the general population: their frequency and relationship to other sleep and mental disorders. J Clin Psychiatry. 1999;60(4):268-276.
93. Ajlouni KM, Ahmad AT, Al-Zahiri MM, et al. Sleepwalking associated with hyperthyroidism. Endocr Pract. 2005;11(1):5-10.

94. Di Gennaro G, Autret A, Mascia A, Onorati P, Sebastiano F, Quarato PP. Night terrors associated with thalamic lesion. Clin Neurophysiol. 2004;115(11):2489-2492.

95. Owens J, Spirito A, Nobile C, Arrigan M. Incidence of parasomnias in children with obstructive sleep apnea. Sleep. 1997;20(12): 1193-1196.

96. Guilleminault C, Kirisoglu C, Bao G, Arias V, Chan A, Li KK. Adult chronic sleepwalking and its treatment based on polysomnography. Brain. 2005;128(5):1062-1069.

97. Kotagal S. Parasomnias in childhood. Sleep Med Rev. 2009;13(2): $157-168$.

98. Hossain JL, Shapiro CM. The prevalence, cost implications, and management of sleep disorders: an overview. Sleep Breath. 2002;6(2): 85-102.

99. Wilson SJ, Nutt D, Alford C, et al. British Association for Psychopharmacology consensus statement on evidence-based treatment of insomnia, parasomnias and circadian rhythm disorders. J Psychopharmacol. 2010;24(11):1577-1601.

100. Sivertsen B, Omvik S, Pallesen S, et al. Cognitive behavioral therapy vs zopiclone for treatment of chronic primary insomnia in older adults: a randomized controlled trial. JAMA. 2006;295(24):2851-2858.

101. Hurwitz TD, Mahowald MW, Schenck CH, Schluter JL, Bundlie SR. A retrospective outcome study and review of hypnosis as treatment of adults with sleepwalking and sleep terror. J Nerv Ment Dis. 1991;179(4):228-233.

102. Tobin JD. Treatment of somnambulism with anticipatory awakening. J Pediatr. 1993;122(3):426-427.

103. Harris M, Grunstein RR. Treatments for somnambulism in adults: assessing the evidence. Sleep Med Rev. 2009;13(4):295-297.

104. Reid W, Haffke E, Chu CC. Diazepam in intractable sleepwalking: a pilot study. Hillside J Clin Psychiatry. 1983;6(1):49-55.

105. Schenck CH, Mahowald MW. Long-term, nightly benzodiazepine treatment of injurious parasomnias and other disorders of disrupted nocturnal sleep in 170 adults. Am J Med. 1996;100(3):333-337.

106. Kierlin L, Littner MR. Parasomnias and antidepressant therapy: a review of the literature. Front Psychiatry. 2011;2:71.

107. Cooper AJ. Treatment of coexistent night-terrors and somnambulism in adults with imipramine and diazepam. J Clin Psychiatry. 1987;48(5): 209-210.

108. Lillywhite A, Wilson S, Nutt D. Successful treatment of night terrors and somnambulism with paroxetine. Br J Psychiatry. 1994;164(4): $551-554$

109. Lam SP, Fong S, Ho C, Yu M, Wing YK. Parasomnia among psychiatric outpatients: a clinical, epidemiologic, cross-sectional study. J Clin Psychiatry. 2008;69(9):1374-1382.
Nature and Science of Sleep

\section{Publish your work in this journal}

Nature and Science of Sleep is an international, peer-reviewed, open access journal covering all aspects of sleep science and sleep medicine, including the neurophysiology and functions of sleep, the genetics of sleep, sleep and society, biological rhythms, dreaming, sleep disorders and therapy, and strategies to optimize healthy sleep. The journal welcomes

\section{Dovepress}

original research, clinical \& epidemiological studies, reviews \& evaluations, case reports and extended reports. The manuscript management system is completely online and includes a very quick and fair peerreview system, which is all easy to use. Visit http://www.dovepress.com/ testimonials.php to read real quotes from published authors. 